\title{
Platelet-rich Plasma in Orthopedics: Efficacy, Evidence, and Evolution of Our Understanding over 10 Years
}

\author{
${ }^{1}$ Sandeep Patel, ${ }^{2}$ Mandeep S Dhillon
}

\begin{abstract}
Introduction: Platelet-rich plasma (PRP) is fast emerging as a minimally invasive treatment option in a wide variety of orthopedic conditions. We were the forerunners in India in its use in osteoarthritis (OA), lateral epicondylitis, plantar fasciitis, and sports injuries. We present our experience with prospective clinical studies and multiple research projects, and have shown some aspects to be reproducible and evidence-based, whereas some areas of application seem to demand more evidence prior to routine recommendation for use.
\end{abstract}

Materials and methods: Since 2009, PRP is in routine use at the Postgraduate Institute of Medical Education and Research (PGIMER); this ensued after our initial struggle of standardizing PRP as a product, followed by its clinical use in early $O A$ knee, followed by use in recalcitrant tennis elbow, recalcitrant plantar fasciitis and various sports injuries. We also carried forward our PRP work with some experimental in vitro studies on anterior cruciate ligament $(A C L)$ regeneration by $P R P$ in a cell culture model. Our work on guinea pig OA model to compare PRP vs normal saline to document histological and biomarkers in $\mathrm{OA}$ is ongoing, and initial experience with that is also presented.

Conclusion: From our experience, and a meta-analysis of the literature, it can be stated that PRP is effective in early degenerative knees (as a short-term modality) and lateral epicondylitis. We also recommend its use in chronic tendinopathies and various sports injuries; however, its use in these situations needs to be limited, as there is conflicting evidence in the literature, and our work on this aspect is preliminary in nature. In the case of $A C L$ regeneration, we found equivocal experimental findings, and more research toward this area is the necessity of the hour.

Keywords: Knee osteoarthritis, Orthobiologics, Platelet-rich plasma, Sports injury.

How to cite this article: Patel S, Dhillon MS. Platelet-rich Plasma in Orthopedics: Efficacy, Evidence, and Evolution of Our Understanding over 10 Years. J Postgrad Med Edu Res 2018;52(2):64-72.

Source of support: Nil

Conflict of interest: None

\footnotetext{
${ }^{1}$ Assistant Professor, ${ }^{2}$ Professor and Head

1,2Department of Orthopedics, Postgraduate Institute of Medical Education and Research, Chandigarh, India

Corresponding Author: Sandeep Patel, Assistant Professor Department of Orthopedics, Postgraduate Institute of Medical Education and Research, Chandigarh, India, Phone: +919901440404, e-mail: sandeepdrpatelortho@gmail.com
}

\section{INTRODUCTION}

Platelet-rich plasma emerged on the orthopedic treatment horizon with a big bang in the early 21st century. Despite a big splash, the initial fervor was somewhat tempered as the indications were expanded, and the evidence presented was considered somewhat controversial. Orthobiologics has now become a recognized branch of orthopedic management, and the leading contender for the least controversial usage is PRP, with its ease of application and autogenous nature.

\section{Mechanism of PRP as a Beneficial Agent}

Platelets contain various granules namely $\alpha, \delta$, and $\lambda ; \alpha$ granules play a pivotal role in platelet function. There are approximately 50 to $80 \alpha$ granules per formed platelet ${ }^{1}$ and contains more than 30 proteins including plateletderived growth factor, transforming growth factor ( $\beta 1$ and $\beta 2$ isomers), platelet factor 4 , interleukin 1, plateletderived angiogenesis factor, vascular endothelial growth factor, epidermal growth factor, platelet-derived endothelial growth factor, epithelial cell growth factor, insulin-like growth factor, and so on. ${ }^{2}$ The healing properties of PRP are based on the production and release of these factors when the platelets are activated. Platelets begin secreting these proteins within 10 minutes of clotting; after the initial release of growth factors, the platelets synthesize and secrete additional such factors for the remaining days of their life span. ${ }^{3}$

\section{Role of PRP in OA}

The pathogenesis of OA is primarily because of the alteration of normal metabolism within joints, which favors increased catabolism and decreased anabolism. Plateletrich plasma helps in addressing the OA joint by acting at various levels. First, they help in improving the cartilage structure by decreasing catabolism, improve anabolism, increase type II collagen and prostaglandin synthesis, and hence, promote the overall chondral remodeling. ${ }^{4,5}$ Second, PRP targets synoviocytes and promotes hyaluronic acid (HA) secretion by increasing expression of hyaluronan synthase 2 . It also switches angiogenesis to a more favorable and balanced state. ${ }^{4,6}$ Third, PRP might also influence the apoptotic pathway by down regulating the expression of programmed cell death-5, thus 
inhibiting the apoptosis of OA chondrocytes. ${ }^{7,8}$ However, the last and probably the most important mechanism of action that explains the well-documented pain reduction, which is also the most prominent and disabling symptom of knee OA, seems to be the anti-inflammatory and antinociceptive role (by regulation of nuclear factor-kappa B and cyclooxygenase-2). ${ }^{9,10}$

\section{Role of PRP in Tendinopathy}

The cocktail of growth factors has also been shown to be effective in providing an ideal environment for healing of tendinopathies; this has been successfully used in the treatment of resistant lateral epicondylitis, resistant plantar fasciitis, rotator cuff tears, hamstring tears, and patellar tendinopathies. It is the success of PRP in treating various tendinopathies in prominent sports persons which brought it to limelight in early 21st century.

\section{Our Role in PRP use in Indian Conditions}

We were the first to begin PRP work in India and started this on an experimental and clinical stage in 2009; our initial efforts were focused on preparing in-house PRP with the help of our Transfusion Medicine Department. Once the PRP was standardized, we started using it in various orthopedic conditions and the compiled data from various applications and studies are presented here. Ours was the first work in the world comparing the efficacy of PRP over placebo in early knee OA, and established that a single injection of PRP could be as effective as two injections of PRP over a period of time. We also conducted an in vivo experimental study on guinea pigs and established the superiority of PRP over normal saline in the prevention of progression of OA.

\section{MATERIALS AND METHODS}

We undertook multiple prospective studies and research projects related to PRP use in orthopedic conditions at Postgraduate Institute of Medical Education and Research, Chandigarh, India.

- We had to struggle initially for the preparation and standardization of PRP with collaboration with Transfusion Medicine Department. After a thorough literature search and laboratory experiments, we worked on various methods of PRP preparation and finally standardized the technique required for our research project on knee OA. There was a lot of concern surrounding leukocyte-rich PRP for OA knee use, and hence, we preferred to use leukocyte-free PRP for our project. ${ }^{11}$ We also evaluated various activating agents and zeroed in on using calcium chloride inside the joint. The ratio of 1:4 ( $1 \mathrm{mLCaCl}_{2}$ for $4 \mathrm{~mL}$ PRP) was arrived at after trying out varying ratios in our experiments.

\section{Evolution of Our Technique for PRP Preparation}

- Initial technique was a single spin technique and the use of leukocyte filter. About $100 \mathrm{~mL}$ of venous blood was drawn under aseptic precautions from the antecubital vein; this was done atraumatically in an effort to avoid irritation and trauma to the platelets which are in a resting state. The blood sample was collected in a $100 \mathrm{~mL}$ bag with citrate phosphate dextrose and adenine as anticoagulant (Fig. 1A). The whole blood was transferred from the blood bag into sterile tubes (50 mL) using a blood transfusion set, inside the biosafety cabinet (BIOAIR-Safe flow 1.2, type II) (Fig. 1B). The tubes were then centrifuged for 15 minutes at 1,500 rpm on a table top centrifuge (Fig. 1C). The blood was separated into PRP and residual red blood cells (RBCs) with the buffy coat (Fig. 1D). Hereafter, the procedure was completely done inside the biosafety cabinet. The PRP was then extracted through a pipette and transferred to a test tube (Fig. 1E). A leukocyte filter (Imugard III-PL, Terumo Penpol company) was then used to filter off the leukocytes (Fig. 1F). The final $P R P$ ready to be injected was supplied in a syringe in a quantity of $8 \mathrm{~mL}$ for a knee (Figs $1 \mathrm{G}$ and $\mathrm{H}$ ).

- Double spin technique-About $50 \mathrm{~mL}$ of blood was drawn from the antecubital vein of the patient using aseptic precautions with efforts to avoid irritation and trauma to platelets which are in a resting state. The blood sample was collected in a blood bag (Terumo Penpol Limited, Thiruvananthapuram, India) with citrate-phosphate-dextrose and adenine as the anticoagulant preservative solution. The whole blood was then transferred from the blood bag into a sterile tube using a blood transfusion set, inside a biosafety cabinet, class IIA (BIOAIR Safe flow 1.2, Euroclone, Siziano, Italy). The whole blood was then centrifuged for 15 minutes at 1,300 rpm inside a table top centrifuge. The blood was thus separated into PRP and residual $\mathrm{RBC}$ s with the buffy coat. The tube was then again brought inside the biosafety cabinet. The PRP was extracted through a pipette and transferred to another sterile tube. It was again subjected to centrifugation for 5 minutes at 2,300 rpm. After this the supernatant platelet poor plasma was pipetted inside the biosafety cabinet into another sterile tube so as to leave behind 16 to $18 \mathrm{~mL}$ plasma along with the platelet pellet at the bottom. The platelet pellet was then resuspended in the remaining plasma as the final PRP, and was dispensed in a sterile syringe. The final PRP volume of 8 to $9 \mathrm{~mL}$ each was dispensed in two sterile syringes.

- Use of commercially available PRP preparations-By the year 2013, after the success of PRP use in various 

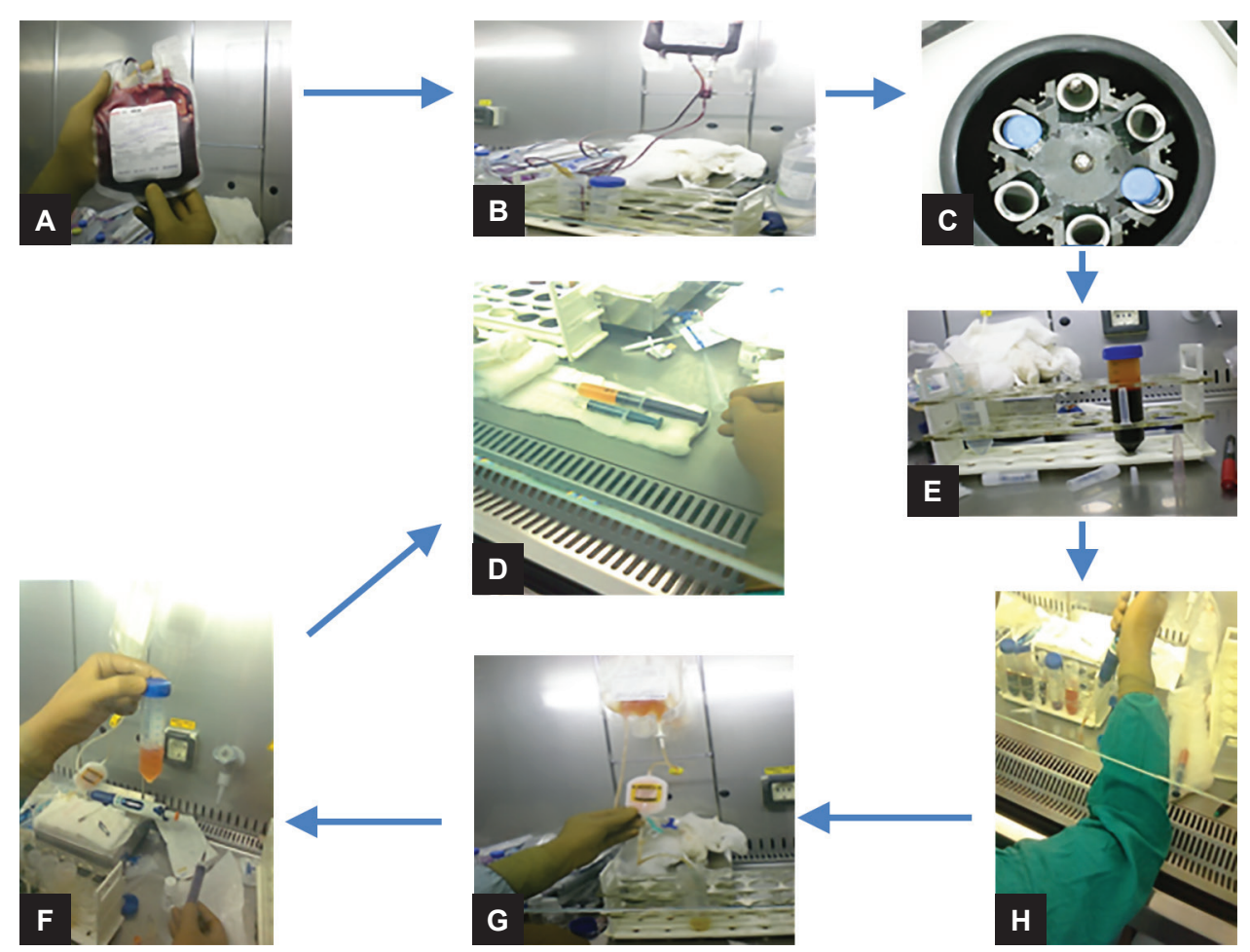

Figs 1A to H: Preparation of leukocyte-free PRP in our transfusion medicine lab

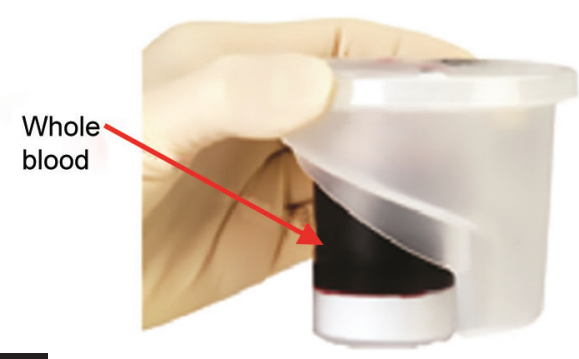

B

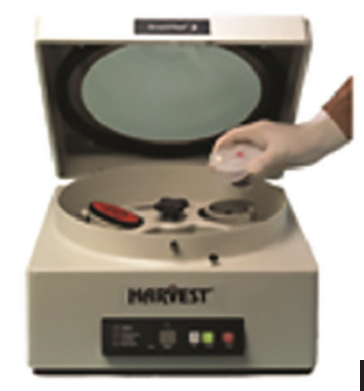

Figs 2A to C: One of commonly used commercially available PRP table top centrifuge devices, which was used for preparing PRP for plantar fasciitis injections. (Lifecell)

orthopedic conditions was reported from studies globally, we Indians got access to commercially available PRP kits; this was easier, faster, and was possible through the available compact table top devices (Fig. 2). This was a major boon, as the PRP application could be extended to other indications. The major drawback of our in-house prepared PRP was that it was available to only specified research projects, after institutional ethical board clearance. Moreover, as it was with collaboration with Transfusion Medicine Department, significant manpower use was required; hence, its use was limited in the routine clinical scenario, as multiple existing projects from various departments were ongoing. The availability of commercial kits allowed us to expand our usage to prospective patient groups.

\section{Methodology of Six Studies done at PGIMER}

1. OA knee study ${ }^{12}$ : We did a double-blinded, randomized, placebo-controlled trial on a total of 78 patients (156 knees) having grade II or III bilateral OA knee. Group I (52 knees) received a single injection of PRP, group II (50 knees) received 2 injections of PRP 3 weeks apart, and group III (46 knees) received a single injection of normal saline as placebo control; $8 \mathrm{~mL}$ PRP which was white blood cell (WBC)-filtered PRP with a platelet count 3 times that of baseline (PRP type $4 \mathrm{~B}$ ) along with $2 \mathrm{~mL} \mathrm{CaCl}_{2}$ (ratio 1:4) as activating agent was injected. Volunteer participants were blinded and subjected to a standardized injection protocol and were assessed on a number of variables [Western Ontario and McMaster Universities Arthritis Index (WOMAC) scoring, visual analog scale (VAS) 


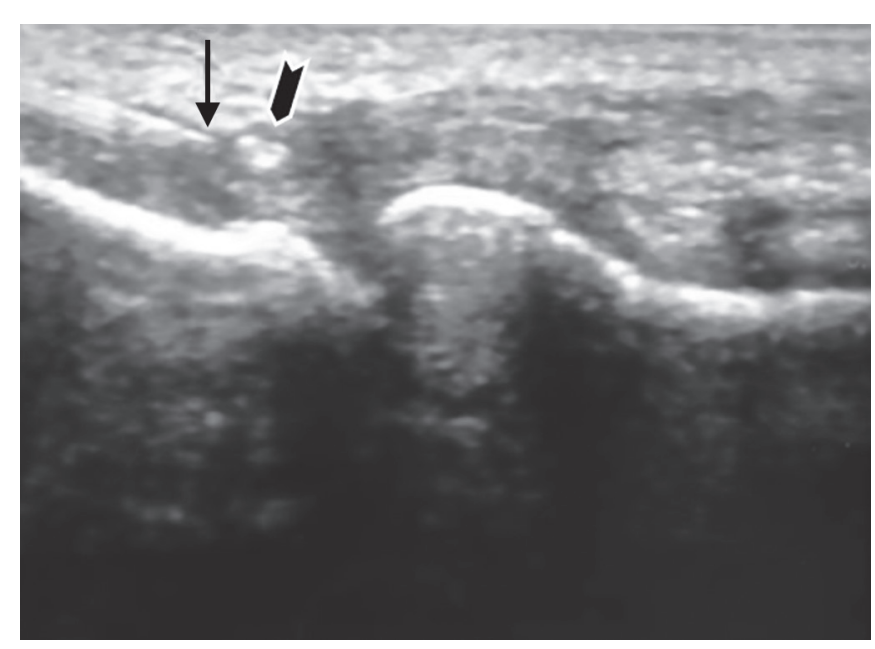

Fig. 3: PRP for tennis elbow: advancement of needle (arrow) into ECRB tendon and PRP being injected (arrow head). Use of ultrasonography improves accuracy

for pain, satisfaction, and adverse effects] before the treatment and at 3 times after treatment (at 1.5, 3, and 6 months) by a blinded observer (Fig. 1).

2. Tennis elbow study ${ }^{13}$ : Patients presenting to our outpatient department (OPD) from January to December 2011 aged 27 to 50 years with painful (VAS >60) and recalcitrant (failed conservative treatment for $>3$ months) tennis elbow after ruling out other pathologies were randomized to receive leukocyte poor PRP (type 4B PRP) $(\mathrm{n}=15)$ or bupivacaine $(\mathrm{n}=10)$ injection. The injection was given under ultrasound guidance into the maximum hypoechoic area of the extensor carpi radialis brevis (ECRB) tendon using the peppering technique (Fig. 3); $3 \mathrm{~mL}$ of PRP and $0.5 \mathrm{~mL}$ of calcium chloride were injected by 5 to 6 passes into the tendon through a single portal. For the bupivacaine group, $3 \mathrm{~mL}$ of bupivacaine and $0.5 \mathrm{~mL}$ of normal saline were injected similarly. Visual analogue scale for pain, modified Mayo clinic performance index (MMCPIE) for elbow function, and Nirschl score for activity-related pain were the outcome measures evaluated at 1, 3, 6, and 12 months by a single assessor.

3. Stimulation of human ACL growth in culture by PRP in an in vitro study ${ }^{14}$ : A controlled laboratory study was designed and ACL remnants were collected from the tibial stump of torn ACL with a punch from 28 patients during arthroscopic ACL reconstruction. Successful primary culture was obtained in 11 out of 28 samples of ACL remnant tissue; cells were isolated, identified, and cultured and were then divided into six groups:

a. Group I: $10 \%$ fetal bovine serum (FBS) + cells +media (taken as control)

b. Group II: Control + 5\% PRP

c. Group III: Control $+5 \%$ PPP

d. Group IV: Control + 10\% PRP e. Group V: Cells + media + 5\% PRP (no FBS)

f. Group VI: Cells + media $+10 \%$ PRP (no FBS)

The cell cultures were analyzed for cell viability and deoxyribonucleic acid (DNA) content to gauge the effect which varying concentration of PRP and PPP have on the cultured cells. Cell viability was assayed by MTT and Annexin V assay, and the DNA content was evaluated by propidium iodide staining and flow cytometry.

4. PRP in recalcitrant plantar fasciitis ${ }^{15}$ : A prospective cohort study was undertaken on patients with plantar fasciitis of minimum 3 months duration, with previous unsuccessful conservative therapy, after exclusion of other causes of heel pain. A total of 60 patients were selected and divided into two groups. The corticosteroid group received a mixture of $40 \mathrm{mg}$ of triamcinolone acetonide (Kenacort, Nicholas Piramal, India) and $3 \mathrm{~mL}$ of $2 \%$ lignocaine (Xylocaine, Aestus Enterprises, India) into the tender spot. In the PRP group, PRP was prepared using $54 \mathrm{~mL}$ blood and $6 \mathrm{~mL}$ of Anticoagulant Citrate Dextrose Solution-Formula A using Smart PReP system (Harvest Technologies Corporation, Plymouth, Massachusetts, USA). The PRP sample obtained was injected similarly to the tender spot. The patients were assessed before and after the injection at 3 months, using VAS, the Foot \& Ankle Disability Index (FADI), and American Foot and Ankle Score (AFAS) (Fig. 2).

5. PRP in insertional tendinosis and muscle tears in sports individuals (ongoing study): This is a case series involving identification of national-level sportspersons (kabaddi, athletics, tennis, etc.) presenting to our OPD and having diagnosed of various insertional tendinoses or muscle tears. These cases were selected after they failed conventional treatment options, and were injected with PRP (method and results are tabulated in Table 1).

6. In vivo experimental study on guinea pigs to investigate the anti-inflammatory and chondroprotective effect of allogeneic PRP in an in vivo experimental study: This study was conducted on 24 DunkinHartley guinea pigs (weighing $~ 700 \mathrm{gm}$ ). Twelve animals (group I) were given intra-articular allogeneic PRP injections (PRP prepared from a different guinea pig by intra-cardiac blood withdrawal and subjecting to two spin technique) three times at weekly intervals in one knee with simultaneous isotonic saline injection to the contralateral knee to act as control. The other 12 animals (group II) underwent similar intervention 1 month later for reproducibility of results. Six animals from each group (subgroups IA, IIA) were euthanized at 3 months and the remaining six (subgroups IB, IIB) at 6 months postintervention. Upon euthanasia, knee joint synovial fluid samples were collected from each 
Table 1: Details of PRP use in sports individuals in various conditions

\begin{tabular}{|c|c|c|c|c|c|}
\hline Condition & Number of patients & $\begin{array}{l}\text { Total } \\
\text { number }\end{array}$ & Clinical picture & $\begin{array}{l}\text { Number of } \\
\text { PRP injections }\end{array}$ & Results \\
\hline $\begin{array}{l}\text { Insertional tendinosis: } \\
\text { Achilles tendon }\end{array}$ & $\begin{array}{l}\text { Cricket fast bowlers } 3 \\
\text { Sprinters } 4 \\
\text { Kabaddi } 4\end{array}$ & 7 & $\begin{array}{l}\text { Pain at retrocalcaneal area, not } \\
\text { responded to 3-week course of } \\
\text { physiotherapy and medications. } \\
\text { Pathology confirmed by MRI }\end{array}$ & $\begin{array}{l}4 \text { patients: } \\
1 \text { injection } \\
2 \text { patients: } \\
2 \text { injections } \\
1 \text { patient: } \\
3 \text { injections }\end{array}$ & $\begin{array}{l}\text { Pain relief in all } 3 \text { fast } \\
\text { bowlers, all } 4 \text { kabaddi } \\
\text { players and } 3 \text { out of } 4 \\
\text { sprinters at their last } \\
\text { follow-up }\end{array}$ \\
\hline Patellar tendinosis & $\begin{array}{l}\text { Weightlifters: } 2 \\
\text { Sprinter: } 1 \\
\text { Nonsportsperson: } 2\end{array}$ & 5 & $\begin{array}{l}\text { Pain at lower pole of patella, not } \\
\text { responding to physiotherapy and } \\
\text { diagnosis confirmed by MRI (signal } \\
\text { changes) }\end{array}$ & $\begin{array}{l}\text { All patients } \\
\text { single } \\
\text { injection }\end{array}$ & $\begin{array}{l}\text { Pain relief in all } 5 \\
\text { patients by the end of } \\
8 \text { weeks }\end{array}$ \\
\hline Hamstring tears & $\begin{array}{l}\text { Sprinter }=1 \\
\text { Hockey }=2 \text { Latin } \\
\text { dancer }=1\end{array}$ & 5 & $\begin{array}{l}2 \text { cases: back of thigh at proximal } \\
\text { third-middle third junction; } \\
\text { tenderness at the site and signal } \\
\text { change on USG and MRI } \\
3 \text { cases: laterally over biceps } \\
\text { femoris at distal third thigh }\end{array}$ & $\begin{array}{l}\text { All patients } \\
\text { single } \\
\text { injection }\end{array}$ & $\begin{array}{l}\text { Pain relief in all } 5 \\
\text { patients }\end{array}$ \\
\hline Quadriceps tears & $\begin{array}{l}\text { Weightlifters: } 2 \\
\text { Kabaddi: } 2\end{array}$ & 4 & & & \\
\hline $\begin{array}{l}\text { Meniscal cyst } \\
\text { (lateral meniscus)_- } \\
\text { extra-articular }\end{array}$ & $\begin{array}{l}\text { Sprinters: } 2 \\
\text { Kabaddi: } 2\end{array}$ & 4 & $\begin{array}{l}\text { Cystic swelling anterolaterally and } \\
\text { occasional pain at the same site. } \\
\text { Confirmed by MRI }\end{array}$ & $\begin{array}{l}\text { All patients } \\
\text { single } \\
\text { injection }\end{array}$ & $\begin{array}{l}\text { Swelling decreased } \\
\text { in } 2 \text { players, and } \\
\text { pain decreased in } \\
3 \text { players }\end{array}$ \\
\hline
\end{tabular}

USG: Ultrasonography; MRI: Magnetic resonance imaging

joint for Cartilage Oligomeric Matrix Protein (COMP) estimation by enzyme-linked immunosorbent assay and bilateral knee joints were harvested for histologic assessment of articular cartilage and synovium.

\section{RESULTS}

OA knee study ${ }^{12}$ : Statistically significant improvement in all WOMAC parameters (pain, stiffness, physical function, and total score) and VAS scores was observed in single-injection and double-injection PRP group in comparison with the normal saline (placebo) group, with the improvement beginning at an average of 16 to 17 days in both groups and the benefits were sustained till the final follow-up at 6 months compared with baseline. However, there was a minimal deterioration at 6 months in comparison to 3rd month follow-up. We also did not notice any significant difference between single injection and double injections of PRP. Small sample size could be responsible for this and a definitive conclusion cannot be drawn based on this. Knees with Ahlbäck grade I fared better than those with grade II. Mild complications, such as nausea and dizziness, which were of short duration, were observed in 6 patients $(22.2 \%)$ in group I and 11 patients $(44 \%)$ in group II.

Tennis elbow study ${ }^{13}$ : Improvement in the following functional scores (VAS for pain, mean MMCPIE score, and mean Nirschl score) was greater in the PRP group than in the bupivacaine group after 3 months (42.5 vs $30.9 \%, 34.1$ vs $27.2 \%$, and 50.7 vs $39.6 \%$ ), 6 months (67.3vs
$20.1 \%, 40.6$ vs $16.3 \%$, and 71.4 vs $31.1 \%$ ), and 1 year (83.2 vs $45.6 \%, 47.0$ vs $21.7 \%$, and 76.6 vs $56.3 \%$ ). The difference in scores between groups was significant at 6 months and 1 year only $(p<0.001)$. In conclusion, leukocyte-free PRP had better outcome in terms of pain and function in recalcitrant tennis elbow (Fig. 3).

PRP in recalcitrant plantar fasciitis ${ }^{15}$ : Both PRP and corticosteroid groups had improvement, which was significant for all postoperative outcome measures (VAS, AFAS, and FADI). However, the improvement was much better in the PRP group than in the corticosteroid group with better foot scores and lower pain scores.

Stimulation of human ACL growth in culture by PRP in an in vitro study ${ }^{14}$ : Analysis of cultured cells showed that addition of PRP ( 5 or $10 \%$ ) increased the viability of ACL cells in 4 out of 11 and promoted cell proliferation in 8 of 11 donor samples; $10 \%$ PRP was more effective than $5 \%$ PRP. However, the difference in effectiveness of $10 \%$ PRP was not significantly better than 5\% PRP; $5 \%$ PPP had no significant effect on cell viability, but it led to an increase in the DNA content in 5 of 11 . There was no statistically significant effect of either PRP or PPP in preventing cell death (depicted by apoptosis rate).

In vivo experimental study on guinea pigs to investigate the anti-inflammatory and chondroprotective effect of allogeneic PRP in an in vivo experimental study: Mean synovitis scores and synovial vascularity were significantly lower in PRP-treated knees as compared with controls at both 3 and 6 months $(p<0.05)$, suggesting better outcome in the 
Platelet-rich Plasma in Orthopedics

Table 2: Meta-analysis of PRP effectiveness in knee OA

\begin{tabular}{|c|c|c|c|c|c|c|}
\hline \multirow[b]{2}{*}{ Study, Year } & \multirow[b]{2}{*}{ Population } & \multirow[b]{2}{*}{ Comparison } & \multirow[b]{2}{*}{ Outcomes assessed } & \multicolumn{2}{|r|}{ Included trials } & \multirow[b]{2}{*}{ Favors PRP } \\
\hline & & & & No. & Design & \\
\hline Dold $2014^{22}$ & $\begin{array}{l}\text { Articular } \\
\text { cartilage } \\
\text { pathology }\end{array}$ & $\begin{array}{l}\text { PRP use (no } \\
\text { comparator specified) }\end{array}$ & Pain, function, health & 10 & $\begin{array}{l}\text { RCT (2) } \\
\text { Prospective cohort (1) } \\
\text { Retrospective cohort (1) } \\
\text { Case series (6) }\end{array}$ & $\begin{array}{l}\text { Yes (but better } \\
\text { evidence needed) }\end{array}$ \\
\hline Laudy $2015^{23}$ & $\begin{array}{l}\text { Knee } \\
\text { Osteoarthritis }\end{array}$ & $\begin{array}{l}\text { Platelet-based product } \\
\text { vs control }\end{array}$ & $\begin{array}{l}\text { Pain, function, } \\
\text { radiographic }\end{array}$ & 10 & $\begin{array}{l}\text { RCT (6) } \\
\text { Prospective cohort (4) }\end{array}$ & $\begin{array}{l}\text { Yes (but better } \\
\text { evidence needed) }\end{array}$ \\
\hline Riboh $2016^{24}$ & $\begin{array}{l}\text { Knee } \\
\text { Osteoarthritis }\end{array}$ & $\begin{array}{l}\text { LP PRP vs LR PRP vs } \\
\text { HA vs placebo }\end{array}$ & $\begin{array}{l}\text { Function, adverse } \\
\text { events }\end{array}$ & 8 & $\begin{array}{l}\mathrm{RCT}(6) \\
\text { Prospective cohort (2) }\end{array}$ & Yes \\
\hline Shen $2017^{25}$ & $\begin{array}{l}\text { Knee } \\
\text { Osteoarthritis }\end{array}$ & PRP vs control & Pain, function & 14 & RCTs & Yes \\
\hline
\end{tabular}

PRP: Platelet rich plasma; LP PRP: Leucocyte poor PRP; LR PRP: Leucocyte rich PRP; HA: Hyaluronic acid; RCT: Randomized controlled trial

PRP group. The result was reproducible in both groups. Mean synovial fluid COMP concentration was significantly lower in PRP-treated knees $(\mathrm{p}<0.05)$ at 3 months only with reproducible results, suggesting slowing of cartilage breakdown; however, there was no difference at 6 months. The mean articular cartilage degeneration was significantly lower in PRP-treated knees in group I at both 3 and 6 months ( $<<0.05)$; however, the result was not reproducible in group II. We concluded that antiinflammatory effect of PRP may form the biologic basis of improvement in clinical symptoms of knee $\mathrm{OA}$ in addition to probable short-term chondroprotective effect.

\section{Ongoing Work at PGIMER}

PRP in insertional tendinosis and muscle tears in elite sportspersons-details are given in Table 1.

\section{DISCUSSION}

Platelet-rich plasma has definitely emerged as a solution to specific orthopedic ailments and the evidence so far is promising in selected subgroups. There are numerous articles coming out every day, with varying degrees of evidentiary support; many practitioners have already started using PRP in their day-to-day practice, and some note of caution has to be injected into this euphoria too. It is important to realize that a few contradictory studies are emerging as well, and some of the evidence presented may also be flawed; hence, one should define the conditions where PRP can be used with benefits, and where it has limited evidence in support.

Early knee OA is definitely one condition where PRP use has been established as superior to placebo. ${ }^{12}$ More than 30 clinical trials have been conducted, and published results over the last 7 years have more or less successfully established the PRP's role in decreasing pain and improving knee function scores. ${ }^{12,16-19}$ Studies comparing PRP with viscosupplements also seem to favor PRP over viscosupplements, barring a few reports. ${ }^{20}$ The overall consensus is that PRP is effective in early degenerative knees (grade I, II) and in relatively young individuals. Studies are ongoing in attempts to establish the role of PRP in other knee pathologies like rheumatoid knee. ${ }^{21} \mathrm{We}$ recently concluded an animal study on guinea pigs, and have established histological and biomarker evidence of beneficial role of PRP in OA knees.

As part of a meta-analysis under publication, in collaboration with McMaster University, we reviewed the above studies and found significant benefits of PRP in early OA (Table 2).

Tendinopathies are another area where PRP has achieved some success. The initial popularity and boost the PRP market received partly owes to its success in highprofile sports persons with muscle tears and tendinopathy. The role of PRP in tennis elbow has been positively established by several authors, and was supplemented by our published data, and is no more debatable. ${ }^{26-29}$ However, it is desirable to try other options prior to PRP use in tennis elbow, and to restrict PRP for recalcitrant cases which have failed other treatment modalities. We have shown that the use of ultrasound for guided injections definitely helps in giving the injection at the right site, and this has also been advised by other authors. ${ }^{13,29}$ However, the role of PRP in other tendinopathies like Achilles tendinopathy has not been encouraging, ${ }^{30,31}$ despite successful usage of PRP in patellar tendinopathies. ${ }^{32,33}$ Plantar fasciitis is also another commonly encountered problem which at times can be frustrating to both the patient and the treating doctor. Our experience with PRP has again shown consistently good results, with support from various studies; however, we recommend that this option should be kept for recalcitrant cases ${ }^{34}$ that fail all conventional modalities.

The role of PRP in ACL regeneration is a controversial topic, despite the hype about its supplemental effects. It is important to note that most published studies are in vitro in nature, and to draw conclusion out of these experimental studies and to begin using it clinically is not justifiable. ${ }^{35-37}$ There are few isolated studies where a PRP scaffold has been used around the repaired torn ACL. 
Nevertheless, there are no strong messages available from the current data to support the PRP use in ACL injury, and this should be considered as purely a research topic where extensive work needs to be done. Our experience with cultured ACL cells supplemented by PRP was equivocal and was restricted to one in vitro trial.

At PGIMER, a dedicated PRP workforce team is regularly engaged in research related to PRP. OA knee has been our focused area of interest and several new animal trials are underway. We are looking at using PRP and HA combinations, which has also been supported by a few trials with contradictory results. ${ }^{38-41}$ Currently, there are issues regarding the right formulation, dosage, and sequence and we are on our way to answer that research question through our animal study. We are also working toward more efficient delivery of PRP into knee joint, by combining PRP with various biocompatible nanoparticles with a hope of delivering targeted and controlled release which we hypothesize to be better than the present traditional PRP. ${ }^{42}$

Along with colleagues from McMaster University and the Pittsburg group (Mohit Bhandari, Freddie Fu, etc.), the senior author was part of a systematic review and updated meta-analysis of randomized controlled trials to provide the current best estimate of treatment effect of PRP in musculoskeletal conditions on patient important outcomes. This still to be published review included 78 randomized controlled trials, with a total of 4,814 patients. Our analysis showed that at 3, 6, and 12 months, there was a significant reduction in pain associated with PRP use. The collated evidence supported the use of PRP in knee OA and lateral epicondylitis with effects sustained up to 1 year postinjection, which was consistent with our PGIMER work also. However, evidence supported a lack of clinical effect in muscle injury, rotator cuff injuries, reconstruction of the ACL, and knee arthroplasty. For knee OA, the effect of PRP was most pronounced when compared with a placebo, but demonstrated no clinical benefit over HA up to 6 months, as well as whole blood up to 1 year. Leukocyte concentration, platelet concentration, or use of an exogenous activator, either independently or when controlling for other indication and treatment characteristics, did not influence treatment effects. We personally are still in favor of WBC filtration for intra-articular usage, but ongoing work will prove or disprove this hypothesis.

With the current level of evidence, the idea of PRP is just a beginning, with the aim of stimulating the reparative processes after injury or degeneration; there is still a long way to go before we can quantify and accurately classify the end product for use.

\section{Issues for Debate in 2018}

Preparation modalities are being debated, with bone bank facilities being the cheapest and most reliable as they can use the other filtered products, and ensure sterility. Exposure to air and potential infection transmission from airborne bacteria or contaminants is a potential issue.

Licensing for PRP will be a problem. Most federal licensing bodies are chemical compound evaluators (like the Food and Drug Administration) and have limited understanding of the concept of PRP. Significant current confusion thus persists, and needs to be resolved. Biological products like stem cells or allografts are a different issue and should not be confused with PRP. However, with a better understanding of individual growth factors, some refinements may come into play with individual growth factor concentration, and application in specific scenarios, becoming the thing of the future.

\section{CONCLUSION}

Our experience over 10 years, as well as our analysis of the published literature, has led us to some conclusion:

1. PRP is effective in early degenerative knees and some chronic tendinopathies, especially lateral epicondylitis. This has been proven by our personal research as well as reviews and meta-analysis conducted by us. However, its use needs to be limited to specific indications, and continuing research toward it use is the necessity of the hour.

2. There is limited evidence to support PRP use in plantar fasciitis; its role in ACL reconstructions and rotator cuff repairs is unsupported by evidence. Our experimental work on the ACL using different concentrations in cultured cells could not support this indication conclusively.

3. PRP production methods need to be standardized, especially in India where regulatory enforcement is limited and probably unscientific at times. We need to understand that PRP is not a chemical, nor is it similar to cultured cells, but is a growth factor-driven compound; disease transmission and carcinogenic activity are not important factors contradicting its use. Nevertheless, some self-driven regulation is mandatory, as commercial interests could dominate evidence-based use.

4. Future directions need to be focused on PRP delivery mechanisms. The key factor could be identification and isolation of various growth factors needed for specific scenarios, and refinements in this could make applications more scientific and successful. We are working on experimental models toward more efficient delivery of PRP into the knee joint, by combining PRP with various biocompatible nanoparticles, hoping for targeted and controlled release. 


\section{REFERENCES}

1. Harrison P, Cramer EM. Platelet alpha-granules. Blood Rev 1993 Mar;7(1):52-62.

2. Boswell SG, Cole BJ, Sundman EA, Karas V, Fortier LA. Platelet-rich plasma: a milieu of bioactive factors. Arthroscopy 2012 Mar;28(3):429-439.

3. Alsousou J, Thompson M, Hulley P, Noble A, Willett K. The biology of platelet-rich plasma and its application in trauma and orthopaedic surgery: a review of the literature. J Bone Joint Surg Br 2009 Aug;91(8):987-996.

4. Akeda K, An HS, Okuma M, Attawia M, Miyamoto K, Thonar EJ, Lenz ME, Sah RL, Masuda K. Platelet-rich plasma stimulates porcine articular chondrocyte proliferation and matrix biosynthesis. Osteoarthritis Cartil 2006 Dec;14(12): 1272-1280.

5. Pereira RC,ScaranariM, Benelli R, Strada P, Reis RL,CanceddaR, Gentili C. Dual effect of platelet lysate on human articular cartilage: a maintenance of chondrogenic potential and a transient proinflammatory activity followed by an inflammation resolution. Tissue Eng Part A 2013 Jun;19(11-12):1476-1488.

6. Anitua E, Sanchez M, Nurden AT, Zalduendo MM, de la Fuente M, Azofra J, Andía I. Platelet released growth factors enhance the secretion of hyaluronic acid and induce hepatocyte growth factor production by synovial fibroblasts from arthritic patients. Rheumatology (Oxf) 2007 Dec;46(12): 1769-1772.

7. Yin Z, Yang X, Jiang Y, Xing L, Xu Y, Lu Y, Ding P, Ma J, Xu Y, Gui J. Platelet-rich plasma combined with agarose as a bioactive scaffold to enhance cartilage repair: an in vitro study. J Biomater Appl 2013 Mar;28(7):1039-1050.

8. Mifune Y, Matsumoto T, Takayama K, Ota S, Li H, Meszaros LB, Usas A, Nagamune K, Gharaibeh B, Fu FH, et al. The effect of platelet-rich plasma on the regenerative therapy of muscle derived stem cells for articular cartilage repair. Osteoarthritis Cartil 2013 Jan;21(1):175-185.

9. Bendinelli P, Matteucci E, Dogliotti G, Corsi MM, Banfi G, Maroni P, Desiderio MA. Molecular basis of anti-inflammatory action of platelet-rich plasma on human chondrocytes: mechanisms of NF-kB inhibition via HGF. J Cell Physiol 2010 Nov;225(3):757-766.

10. Wu CC, Chen WH, Zao B, Lai PL, Lin TC, Lo HY, Shieh YH, $\mathrm{Wu} \mathrm{CH}$, Deng WP. Regenerative potentials of platelet-rich plasma enhanced by collagen in retrieving proinflammatory cytokine-inhibited chondrogenesis. Biomaterials 2011 Sep;32(25):5847-5854.

11. Dhillon M, Patel S, Bali K. Platelet-rich plasma intra-articular knee injections for the treatment of degenerative cartilage lesions and osteoarthritis. Knee Surg Sports Traumatol Arthrosc 2011 May;19(5):863-864, author reply 865-866.

12. Patel S, Dhillon MS, Aggarwal S, Marwaha N, Jain A. Treatment with platelet-rich plasma is more effective than placebo for knee osteoarthritis: a prospective, double-blind, randomized trial. Am J Sports Med 2013 Feb;41(2):356-364.

13. Behera P, Dhillon M, Aggarwal A, Marwaha N, Prakash M. Leukocyte-poor platelet-rich plasma versus bupivacaine for recalcitrant lateral epicondylar tendinopathy. J Orthop Surg (Hong Kong) 2015 Apr;23(1):6-10.

14. Dhillon MS, Karna SK, Dhatt SS, Behera P, Bhatia A. Can platelet rich plasma stimulate human ACL growth in culture? A preliminary experience. Muscles Ligaments Tendons J 2015 Oct 20;5(3):156-161.
15. Shetty VD, Dhillon M, Hegde C, Jagtap P, Shetty S. A study to compare the efficacy of corticosteroid therapy with plateletrich plasma therapy in recalcitrant plantar fasciitis: a preliminary report. Foot Ankle Surg 2014 Mar;20(1):10-13.

16. Sanchez M, Fiz N, Azofra J, Usabiaga J, Aduriz Recalde E, Garcia Gutierrez A, Albillos J, Gárate R, Aguirre JJ, Padilla S, et al. A randomized clinical trial evaluating plasma rich in growth factors (PRGF-Endoret) versus hyaluronic acid in the short-term treatment of symptomatic knee osteoarthritis. Arthroscopy 2012 Aug;28(8):1070-1078.

17. Spakova T, Rosocha J, Lacko M, Harvanová D, Gharaibeh A. Treatment of knee joint osteoarthritis with autologous plateletrich plasma in comparison with hyaluronic acid. Am J Phys Med Rehabil 2012 May;91:411-417.

18. Cerza F, Carnì S, Carcangiu A, Di Vavo I, Schiavilla V, Pecora A, De Biasi G, Ciuffreda M. Comparison between hyaluronic acid and platelet-rich plasma, intraarticular infiltration in the treatment of gonarthrosis. Am J Sports Med 2012 Dec;40(12): 2822-2827.

19. Kon E, Mandelbaum B, Buda R, Filardo G, Delcogliano M, Timoncini A, Fornasari PM, Giannini S, Marcacci M. Plateletrich plasma intraarticular injection versus hyaluronic acid viscosupplementation as treatments for cartilage pathology: from early degeneration to osteoarthritis. Arthroscopy 2011 Nov;27(11):1490-1501.

20. Filardo G, Di Matteo B, Di Martino A, Merli ML, Cenacchi A, Fornasari P, Marcacci M, Kon E. Platelet-rich plasma intraarticular knee injections show no superiority versus viscosupplementation: a randomized controlled trial. Am J Sports Med 2015 Jul;43(7):1575-1582.

21. Lippross S, Moeller B, Haas H, Tohidnezhad M, Steubesand N, Wruck CJ, Kurz B, Seekamp A, Pufe T, Varoga D. Intraarticular injection of platelet-rich plasma reduces inflammation in a pig model of rheumatoid arthritis of the knee joint. Arthritis Rheumatism 2011 Nov;63(11):3344-3353.

22. Dold AP, Zywiel MG, Taylor DW, Dwyer T, Theodoropoulos J. Platelet-rich plasma in the management of articular cartilage pathology: a systematic review. Clin J Sport Med 2014 Jan;24(1):31-43.

23. Laudy AB, Bakker EW, Rekers M, Moen MH. Efficacy of platelet-rich plasma injections in osteoarthritis of the knee: a systematic review and meta-analysis. Br J Sports Med 2015 May;49(10):657-672.

24. Riboh JC, Saltzman BM, Yanke AB, Fortier L, Cole BJ. Effect of leukocyte concentration on the efficacy of platelet-rich plasma in the treatment of knee osteoarthritis. Am J Sports Med 2016 Mar;44(3):792-800.

25. Shen L, Yuan T, Chen S, Xie X, Zhang C. The temporal effect of platelet-rich plasma on pain and physical function in the treatment of knee osteoarthritis: systematic review and metaanalysis of randomized controlled trials. J Orthop Surg Res 2017 Dec;12(1):1-12.

26. Creaney L, Wallace A, Curtis M, Connell D. Growth factorbased therapies provide additional benefit beyond physical therapy in resistant elbow tendinopathy: a prospective, single-blind, randomised trial of autologous blood injections versus platelet-rich plasma injections. Br J Sports Med 2011 Sep;45(12):966-971.

27. Peerbooms JC, Sluimer J, Bruijn DJ, Gosens T. Positive effect of an autologous platelet concentrate in lateral epicondylitis in a double-blind randomized controlled trial: platelet-rich 
plasma versus corticosteroid injection with a 1-year follow-up. Am J Sports Med 2010 Feb;38(2):255-262.

28. Thanasas C, Papadimitriou G, Charalambidis C, Paraskevopoulos I, Papanikolaou A. Platelet-rich plasma versus autologous whole blood for the treatment of chronic lateral elbow epicondylitis: a randomized controlled clinical trial. Am J Sports Med 2011 Oct;39(10):2130-2134.

29. Mishra AK, Skrepnik NV, Edwards SG, Jones GL, Sampson S, Vermillion DA, Ramsey ML, Karli DC, Rettig AC. Efficacy of platelet-rich plasma for chronic tennis elbow: a double-blind, prospective, multicenter, randomized controlled trial of 230 patients. Am J Sports Med 2014 Feb;42(2):463-471.

30. De Vos RJ, Weir A, Tol JL, Verhaar JA, Weinans H, van Schie HT. No effects of PRP on ultrasonographic tendon structure and neovascularisation in chronic midportion Achilles tendinopathy. Br J Sports Med 2011 Apr;45(5):387-392.

31. Schepull T, KvistJ, Norrman H, Trinks M, Berlin G, Aspenberg P. Autologous platelets have no effect on the healing of human Achilles tendon ruptures: a randomized single-blind study. Am J Sports Med 2011 Jan;39(1):38-47.

32. Filardo G, Kon E, Della Villa S, Vincentelli F, Fornasari PM, Marcacci M. Use of platelet-rich plasma for the treatment of refractory jumper's knee. Int Orthop 2010 Aug;34(6):909-915.

33. Gosens T, Den Oudsten BL, Fievez E, van't Spijker P, Fievez A. Pain and activity levels before and after platelet-rich plasma injection treatment of patellar tendinopathy: a prospective cohort study and the influence of previous treatments. Int Orthop 2012 Sep;36(9):1941-1946.

34. Barrett S, Erredge S. Growth factors for chronic plantar fasciitis. Podiatr Today 2004;17:37-42.

35. Kanazawa T,Soejima T,NoguchiK, TabuchiK,Noyama M,Nakamura K, Shiba N. Tendon-to-bone healing using autologous bone marrow-derived mesenchymal stem cells in ACL reconstruction without a tibial bone tunnel-a histological study. Muscles Ligaments Tendons J 2014 Apr-Jun;4(2): 201-206.

36. Lovric V, Kanazawa T, Nakamura Y, Oliver RA, Yu Y, Walsh WR. Effects of gaps induced into the ACL tendon graft on tendon-bone healing in a rodent ACL reconstruction model. Muscles Ligaments Tendons J 2012 Feb;1(3):91-99.

37. Murray MM, Spindler KP, Abreu E, Muller JA, Nedder A, Kelly M, Frino J, Zurakowski D, Valenza M, Snyder BD, et al. Collagen-platelet rich plasma hydrogel enhances primary repair of the porcine anterior cruciate ligament. J Orthop Res 2007;25(1):81-91.

38. Patel S, Dhillon MS, Bansal T. PRP and HA for hip osteoarthritis: letter to the editor. Am J Sports Med 2016 Sep;44(9): NP44.

39. Patel S, Dhillon MS. The anti-inflammatory and matrix restorative mechanisms of platelet-rich plasma in osteoarthritis: letter to the editor. Am J Sports Med 2014 Jun:42(6): NP30-1.

40. Chen WH, Lo WC, Hsu WC, Wei HJ, Liu HY, Lee $\mathrm{CH}$, Chen SYT, Shieh YH, Williams DF, Deng WP. Synergistic anabolic actions of hyaluronic acid and platelet-rich plasma on cartilage regeneration in osteoarthritis therapy. Biomaterials 2014 Dec;35(36):9599-9607.

41. Dallari D, Stagni C, Rani N, Sabbioni G, Pelotti P, Torricelli P, Tschon M, Giavaresi G. Ultrasound-guided injection of platelet-rich plasma and hyaluronic acid, separately and in combination, for hip osteoarthritis: a randomized controlled study. Am J Sports Med 2016 Jan;44(3):664-671.

42. Dhillon MS, Patel S, John R. PRP in OA knee-update, current confusions and future options. SICOT J 2017 Mar;3:27. 